\title{
Trabalho informal no sistema capitalista: uma análise do perfil do pintor de paredes na Construção civil do município de Abaeté/MG
}

\author{
Informal work in the capitalism: an analysis of the painter in civil construction of \\ Abaeté/MG
}

José Edson Martins*

\begin{abstract}
Resumo:
Diante das mudanças no mundo do trabalho, este artigo ${ }^{1}$ tenta construir um perfil do pintor de paredes informal da construção civil do município de Abaeté/MG articulando suas dimensões específicas com as dimensões do sistema capitalista sob a perspectiva marxista. O estudo, não só retrata algumas singularidades do pintor informal, mas também evidencia a precarização das relações de trabalho consubstanciadas na violação de direitos, na falta de representação sindical e na existência de contratos de trabalho paralelos fundamentados na transgressão da legislação trabalhista.
\end{abstract}

Palavras-chave: Trabalho informal. Pintor de paredes. Sserviço social.

\begin{abstract}
:
This article attempts to build a profile of house painter informal construction civil municipality of Abaeté/MG articulating dimensions with their specific dimensions of the capitalist system from the perspective Marxist. The study, in some pictures singularities of the informal painter, but also highlights theprecarious employment relationships workembodied in violation of rights, lack of union representation, the existence of employment contracts grounded in the transgression of the parallel labor laws.
\end{abstract}

Keyword: Informal work. Painter walls. Social service.

\section{Introdução}

Na contemporaneidade, as mudanças ocorridas no mundo do trabalho a partir dos anos 1970, causadas principalmente pelo advento do neoliberalismo e do processo de reestruturação produtiva, desdobraram-se no desemprego estrutural, na expansão do

\footnotetext{
*Fundação Educacional de Divinópolis - FUNEDI Associada à Universidade do Estado de Minas Gerais UEMG. joseedsonm@hotmail.com

${ }^{1}$ Este artigo é fruto do Trabalho de Conclusão de Curso apresentado a FUNEDI/UEMG, Abaeté/MG em 2010, para graduação no curso de Serviço Social.
} 
trabalho informal ${ }^{2}$ e na precarização das relações de trabalho afetando “[...] a materialidade e a subjetividade do ser que vive do trabalho [...]" (ANTUNES, 2000, p. 149) e, consequentemente, abalando a classe trabalhadora que se torna mais heterogênea, fragmentada e complexa (ANTUNES, 2000, p.170).

No Brasil, essas mudanças também afetaram o município de Abaeté $/ \mathrm{MG}^{3}$ causando a precarização das relações de trabalho perceptível no trabalho informal presente no cotidiano da cidade, principalmente na construção civil. No entanto, a inexistência de pesquisas ou estudos acerca do trabalho informal ${ }^{4}$ na construção civil de Abaeté que revelem a dimensão real do problema dificulta a construção de estratégias sociais, econômicas e políticas para a reversão ou amenização da precarização das condições de trabalho desse segmento. Por isso, Abaeté, bem como os demais municípios de pequeno porte, necessitam de pesquisas que desvelem a realidade social compreendendo as suas peculiaridades dentro dos movimentos globais sob a direção da racionalidade capitalista. Nessa direção, este estudo, não só tenta construir um perfil do pintor de paredes que atua na informalidade na construção civil da cidade de Abaeté, mas também busca, ao mesmo tempo, destacar as relações e articulações do trabalho informal do pintor de paredes com as mudanças no mundo do trabalho considerando, neste caso, que o especifico (trabalho informal) conserva suas particularidades diante do geral (sistema capitalista), uma vez que faz parte do todo e suas múltiplas dimensões interagem com o geral, mas não constitui a totalidade em si.

Levando em consideração isso, a pesquisa de campo que deu origem a este artigo foi realizada no período de 05/08/2010 a 10/09/2010 com 10 (dez) pintores de paredes inseridos no setor informal da construção civil do município de Abaeté-MG. A pesquisa foi qualitativa e quantitativa, assim sendo os dados foram auferidos por meio de um questionário misto

\footnotetext{
${ }^{2}$ Segundo Tavares (2004, p. 27) o “[...] relatório sobre Emprego no Mundo [BIT/1998-99] assinala que nos países em desenvolvimento a maioria dos empregos novos são criados no setor informal, que já ocupa aproximadamente 500 milhões de pessoas."

${ }^{3}$ O município de Abaeté está localizado no estado de Minas Gerais (MG), Brasil, especificamente no centrooeste mineiro. Segundo o IBGE (2010) a cidade possui 22.690 habitantes. O nome da cidade foi "[...] retirado do rio que afluía ao município e servia de designação para aqueles que margeavam a área do São Francisco, desde o rio Bambuí até Paracatu, região conhecida como os sertões do Abaeté-MG" (NORONHA apud MIRANDA; NOGUEIRA, 2008, p. 25).

${ }^{4}$ Mesmo o trabalho informal não se configurando como um fenômeno novo no mundo do trabalho ainda não se observa a inexistência de um consenso entre os estudiosos do tema, principalmente, no que se refere à definição conceitual de informalidade. Diante disso, esse trabalho não tem a pretensão de resolver a polêmica que perpassa o conceito de informalidade, mas somente contribuir para a reflexão do tema.
} 
contendo 10 (dez) perguntas fechadas e 2 (duas) abertas. Os entrevistados foram selecionados pelo tempo de experiência profissional na área, assim sendo foi aplicado um questionário estruturado aos pintores com mais de cinco 5 (cinco) anos no setor informal da construção civil. Os dados foram analisados com base na teoria Marxista ${ }^{5}$. É importante salientar que durante a pesquisa não foi constatada a existência de dados concretos ou pesquisas no município que definam o número aproximado de pintores existentes na cidade. Posto isso passo a analise dos dados da pesquisa.

\section{Desemprego}

Embora, na cidade de Abaeté-MG predomine pequenas e médias empresas e a atividade agropecuária tenha a maior expressividade na economia local, observa-se que a economia e a vida social do município são afetadas pelas mudanças no mundo do trabalho desencadeadas pelo processo de reestruturação produtiva e o advento do neoliberalismo ${ }^{6}$ sob a direção do capital na medida em que "o modo de produção da vida material condiciona o processo da vida social, política e espiritual" (MARX apud HARNECKER, 1971, p. 133). Nessa concepção, o desemprego decorrente, principalmente desses dois processos, também faz parte do cotidiano do município que por sua vez faz da atividade informal do pintor de paredes na construção civil uma possível alternativa de sobrevivência diante do desemprego e do processo de "desproletarização do trabalho industrial fabril." (ANTUNES, 2000, p. 47).

Segundo a pesquisa, $70 \%$ dos pintores entrevistados apontaram o desemprego como a principal causa para sua inserção no setor informal como pintor de paredes na

\footnotetext{
${ }^{5}$ Harnecker (1971, p. 134) afirma que: “A concepção materialista da história parte do princípio de que a produção e, junto com ela, o intercâmbio de seus produtos, constituem a base de toda a ordem social, que em toda sociedade que se apresenta na história, a distribuição dos produtos e, com ela, a articulação social em classes ou estamentos, orienta-se pelo que se produz e como se produz, assim como pelo modo como se troca o produto."

${ }^{6} \mathrm{O}$ advento do neoliberalismo, que possui caráter mais político, nasce nos anos 1940 se afirmando nos anos 1970 quando o sistema econômico capitalista entra em crise econômica (ANDERSON apud SADER, 1995, p. 10). As políticas neoliberais preconizam um Estado mínimo no sentido de gastar o mínimo com políticas sociais e o mínimo de intervenção estatal na esfera econômica (ANDERSON apud SADER, 1995, p. 14-15). Por outro lado, o processo de reestruturação produtiva, que possui natureza mais econômica, surge em resposta, segundo Antunes (2001), à crise estrutural do sistema capitalista evidente na queda da taxa de lucro, esgotamento do modelo de produção taylorista e fordista, hipertrofia da esfera financeira, maior concentração de capitais, crise do Welfare State e incremento acentuado de privatização (ANDERSON apud SADER, 1995, p. 29-30).
} 
construção civil do município de Abaeté. Alguns desses pintores informais como Rogério ${ }^{7}$ (45 anos) e Marcos (47 anos) trabalhavam antes em uma empresa chamada CAF, mas foram demitidos nos anos 1990 quando a empresa terceirizou o setor no qual trabalhavam. Paulo (47 anos), irmão de Rogério e Marcos, trabalhava em uma pequena fabrica de tijolos do pai que foi fechada devido à perda de competividade no mercado local e, consequentemente, perda de mercado para outras empresas maiores. Mateus (36 anos) e Renato (34 anos) trabalhavam como vaqueiros na zona rural. O primeiro trabalhava em um pequeno sítio do pai ficando desempregado ao mudar para a cidade e o segundo ao pedir demissão do emprego para buscar melhores condições de trabalho e vida na zona urbana. Enquanto o desemprego vivenciado por Sebastião (19 anos) e André (21 anos) tem como origem a dificuldade de inserção no mercado formal causado pela baixa capacidade da esfera de produção criar novos empregos. Em ambos os casos o trabalho informal como pintor de paredes surgir como alternativa à exclusão do mercado formal de trabalho que só pode ser pensada, a fim de elucidar as bases materiais do desemprego estrutural, a partir das mudanças no mundo do trabalho.

Por outro lado, $20 \%$ dos entrevistados se inseriram no mercado informal por opção pessoal. Trabalhavam antes nos respectivos empregos: Gilmar (33 anos) era segurança no Banco do Brasil e Renato (32 anos) trocador de ônibus. O primeiro em uma conversa informal relatou que pediu demissão por causa do baixo salário e da rotina que considerou chata e estressante, pois ficava o dia todo em pé, sem fazer nada, olhando as pessoas irem de um lado para o outro. Já Renato afirma ter mudado de serviço em decorrência do baixo salário e da rotina cansativa.

Nesse caso, a insatisfação com o emprego cooperou para que mudassem de área de trabalho, na medida em que no modo de produção capitalista o "[...] trabalho no qual o homem se exterioriza é um trabalho de auto-sacrifício, de mortificação" (MARX, 2004, p. 83), ao invés de ser fonte de satisfação, afirmação e desenvolvimento do ser humano. Por isso migraram do mercado formal para o mercado informal no âmbito da construção civil em busca de certo grau de satisfação pessoal, autonomia, liberdade e melhoria salarial. Contudo, mesmo que o setor informal seja de alguma forma regido por uma

\footnotetext{
7 Todos os nomes utilizados aqui são fictícios para resguardar a identidade dos entrevistados que não quiseram que seus nomes fossem divulgados.
} 
lógica distinta do sistema de assalariamento, o trabalho do pintor informal está condicionado, em última instância ${ }^{8}$, ao modo de produção capitalista. Sendo assim, não foge a lógica do trabalho enquanto auto-sacrifício, já que "o trabalhador só se sente, por conseguinte, e em primeiro lugar, junto a si [quando] fora do trabalho e fora de si [quando] no trabalho" de modo que o trabalho para o pintor informal "não é [...] a satisfação de uma carência, mas somente um meio para satisfazer necessidades fora dele." (MARX, 2004, p. 83).

Apenas um dos entrevistados apresentou motivo diferente para sua inserção no mercado informal como pintor. Nas palavras de Tiago (20 anos) o motivo é assim colocado: "meu pai me obrigou a trabalho porque tava vagabundando na escola". Nesse caso, observa-se que o pai utilizou o seu poder para coagir o filho à inserção precária no mercado informal. É importante destacar que o filho foi forçado a trabalhar para o próprio pai. Isso será visto mais adiante quando abordaremos as relações familiares que permeiam o fazer do pintor informal da construção civil em Abaeté.

Concordamos aqui que o pintor informal possui um pouco mais de liberdade e autonomia que alguns trabalhadores formais, seja pela quase inexistência da figura do patrão, hierarquia flexível e menos rígida dentro do processo de produção do serviço de pintura ou pela quase inexistência de vínculos impessoais e meramente de mercado entre o pintor informal/patrão e o pintor informal/trabalhador. No entanto, "o trabalho árduo é eufemisticamente confundido com 'empreendimento', as virtudes da independência com 'liberdade' e o trabalho por conta-própria como 'realização pessoal'” (MALAGUTI apud TAVARES, 2004, p. 44) criando falsos valores que ao serem defrontados com a realidade concreta se esvaziam de sentido.

O que foi exposto acima nos leva a pensar que as características do setor informal propiciam a introdução do trabalhador na construção civil do município de Abaeté como pintor de paredes seja em opção ao desemprego, seja por opção pessoal ou outro motivo. Entre essas características chamo a atenção aqui para a facilidade de acesso à atividade, mercado desregulamentado, qualificação profissional adquirida fora dos sistemas oficiais de formação e o emprego de tecnologia que privilegia o recurso à mão-

\footnotetext{
${ }^{8}$ Para Engels (apud HARNECKER, 1971, p. 96) “o desenvolvimento político, jurídico, filosófico, religioso, literário, artístico etc, descansa no desenvolvimento econômico. Mas todos eles também repercutem uns sobre os outros e sobre a base da necessidade econômica que se impõe sempre, em última instância."
} 
de-obra (CACCIAMALI, 1983, p. 31). Essa última característica contribui para que a construção civil de Abaeté crie muitos postos de trabalho e, consequentemente, absorva um grande numero de trabalhadores excluídos de outras esferas da produção capitalista. No entanto, o trabalho na construção civil, particularmente o trabalho do pintor, é marcado pela precarização das relações de trabalho como pode ser visto adiante.

\section{Idade}

Na era da mundialização do capital, as metamorfoses no mundo do trabalho que afetam países centrais e países periféricos, também atingem, mesmo que em menor grau ou intensidade, as pequenas cidades, como se observa na pesquisa que indica no município de Abaeté um processo que "[...] exclui os mais jovens e os mais velhos [...]" (ANTUNES, 2000, p. 50) do mercado de trabalho formal.

Nesta linha de raciocínio, os trabalhadores mais velhos, com mais de quarenta anos, representam $30 \%$ dos entrevistados e, uma vez desempregados, raramente conseguem se qualificar para uma reinserção no mercado de trabalho (ANTUNES, 2000, p. 283) engrossando assim, como evidencia a pesquisa, a fileira dos trabalhadores informais. Enquanto, por outro lado, os jovens ${ }^{9}$ (18 a 28 anos) que representam $30 \%$ dos entrevistados, inseriram-se no mercado de trabalho informal pela baixa capacidade da esfera produtiva de absorver esse contingente de mão-de-obra emergente devido à introdução de novas tecnologias poupadoras de mão-de-obra na esfera produtiva, reestruturação produtiva, neoliberalismo, enfim, a meta do capital consiste em obter lucro e não, ao contrário, criar novos empregos.

O outro grupo de entrevistados, compreendido entre o grupo de jovens e idosos, que representam $40 \%$ do total, podem ser pensados a partir dos dois extremos, já que alguns foram excluídos do mercado de trabalho formal e, em alternativa ao desemprego, se inseriram como pintores informais na construção civil, enquanto outros se inseriram nesse mercado ainda na juventude, permanecendo até os dias atuais. Entre estes, alguns já exerceram outras atividades no mercado formal, mas por “opção

\footnotetext{
${ }^{9}$ Apesar desse estudo não ter como foco o trabalho infantil na construção civil de Abaeté cuja prática priva crianças e adolescentes do desenvolvimento social, psicológico, mental, e rouba a sua infância, tal trabalho se encontra também presente nesse setor econômico, principalmente, nas atividades de pintor e eletricista por serem consideradas menos penosas.
} 
pessoal" ou desemprego retornaram à antiga profissão de pintor. Nesse caso a reinserção do ex-pintor na produção do serviço de pintura é facilitada pela sua experiência profissional na área, já que o trabalho do pintor de paredes exige certa qualificação profissional, como veremos a seguir.

\section{Escolaridade}

Conforme a pesquisa, $60 \%$ dos entrevistados possuem somente o ensino primário, $20 \%$ o ensino fundamental e $20 \%$ estão concluindo o ensino médio. Esses dados indicam que o baixo grau de escolaridade dos pintores informais colabora de alguma forma, não só para a sua introdução no setor informal, na medida em que um alto grau de qualificação profissional constitui requisito básico para a inserção no centro da produção capitalista, mas também para a sua permanência nessa atividade, uma vez que a baixa escolaridade dificulta a mobilidade ou transição da periferia da produção capitalista para o seu centro, bem como para a esfera da circulação de mercadorias ou financeira.

Portanto, na atualidade pensar a inserção do trabalhador no mercado de trabalho central ou periférico é refletir acerca da qualificação da mão-de-obra e, deste modo, do grau de escolaridade do trabalhador, visto que a qualificação profissional em nossa sociedade, geralmente é adquirida por meio da educação em centros oficiais de educação e formação profissional.

Contudo seria ingenuidade explicar a informalidade proveniente da atividade do pintor na construção civil do município de Abaeté somente pelo viés da qualificação profissional. Isso seria ignorar as bases materiais desse processo, ou seja, as mudanças no mundo do trabalho que provocam o desemprego estrutural, a expansão da informalidade e a precarização das relações de trabalho, assim como desconsiderar a existência de trabalhadores qualificados no setor informal. Assim sendo, o baixo grau de escolaridade dos pintores informais não deve ser aqui entendido como uma determinante para a sua inserção no setor informal, mas somente um dos fatores que colabora para tal.

A não exigência de um alto grau de escolaridade para o exercício do ofício de pintor facilita a introdução no setor informal uma vez que essa atividade, ao contrário das atividades desempenhadas no centro da produção capitalista, não exige qualificação profissional adquirida em instituições oficiais de formação nem um alto grau de escolaridade. Geralmente, 
a qualificação profissional no setor informal é adquirida fora dessas instituições (CACCIAMALI, 1983, p. 31). Tal qualificação, na construção civil do município de Abaeté, é adquirida, na maioria das vezes, de duas formas, isso não quer dizer que não haja outras formas de adquiri-la, contudo são estas as formas de praxe.

$\mathrm{Na}$ primeira, o trabalhador apropria-se de alguns conhecimentos básicos de pintura, como preparar as paredes, rolar tinta e recortar com tinta a parede, pintando a sua própria casa, a de um parente ou vizinho, e recebendo em alguns casos orientações ou dicas de um pintor profissional. Muitas vezes esse "pintor amador" de final de semana, ao ficar desempregado por algum motivo insere-se na construção civil como ajudante de outro pintor ou como pintor informal/patrão. Quando participa da produção do serviço de pintura como pintor informal/patrão, tende a forçar o preço médio do serviço de pintura para baixo, visto que geralmente para conquistar clientela e se manter no mercado necessita trabalhar abaixo do preço médio cobrado.

A outra forma consiste em tornar-se ajudante de pintor de paredes profissional. Nessa situação, o pintor profissional ensina a seu ajudante, geralmente alguém da família, os conhecimentos de pintura necessários para realização do serviço, isto é, pintar determina construção. O ajudante, por meio da orientação, observação e da prática cotidiana, aprende o passo a passo do serviço de pintura. O tempo de duração da aprendizagem, ou seja, o tempo para passar de ajudante ${ }^{10}$ a pintor profissional varia de pessoa para pessoa. Alguns nunca deixam de ser ajudantes seja por dificuldade de aprendizado, dificuldade do pintor em ensiná-lo ou desinteresse.

Embora, o processo de produção do serviço de pintura informal seja fragmentado em partes ou operações, isso não impede "[...] que o trabalhador apreenda todo o processo que origina o produto final ou determinado serviço" (CACCIAMALI, 1983, p. 32). No entanto, o pintor informal domina somente o processo de pintura, ou melhor, parte do processo de produção da construção civil, marcado pela fragmentação do trabalho. Nesse sentido, na construção civil, o produto final ou a obra acabada (casa, edifícios e outras) resulta do trabalho coletivo que combina os diferentes trabalhos: pedreiro,

${ }^{10} \mathrm{O}$ ajudante de pintor é considerado aqui, do ponto de vista do conhecimento, como o trabalhador que está em fase de aprendizado ou domina apenas parte do processo de produção dos serviços de pintura, enquanto o pintor profissional domina todo o processo e, por isso seria o instrutor do ajudante. No entanto, do ponto de vista dos meios de produção um pintor profissional pode participar na produção dos serviços de pintura como ajudante, como pode ser observado pela pesquisa. 
eletricista, pintor, servente de pedreiro e outros que compõem o processo de produção da construção civil. Logo, a divisão técnica e social do trabalho e, consequentemente, a especialização presente em outros ramos da produção capitalista, também, está presente na construção civil. Além disso, observa-se nesse processo de produção, a divisão entre planejamento e execução típica do Taylorismo (PINTO, 2007, p. 37), na medida em que os engenheiros e arquitetos planejam ou projetam a construção, enquanto os demais trabalhadores da construção civil excutam o projeto, isto é, constroem as obras projetadas.

Ainda, do ponto de vista da divisão do trabalho o saber profissional do pintor informal sustenta uma micro-divisão do trabalho no seio da própria produção do serviço de pintura na medida em que aquele que domina o conhecimento de todo o processo de produção do serviço de pintura é considerado pintor e, por conseguinte, aufere um valor, em termos de salário, superior ao auxiliar ou aprendiz, que ainda está em fase de aprendizagem ou qualificação profissional. Esse saber que estabelece hierarquia e certo controle sobre o processo de pintura, também, cria condições favoráveis para o trabalho autônomo ou "um biquinho [depois do horário de trabalho] para pintar, para tirar um extra" como diz um dos entrevistados.

Além disso, esse saber profissional possibilita ao pintor informal certa autonomia em termos de organização do trabalho no seio do processo de produção do serviço de pintura. No entanto, essa autonomia é restrita, já que só existe em termos de intensificação do trabalho, uma vez que a liberdade de organização do trabalho acontece dentro de determinadas circunstâncias condicionadas à lógica capitalista, bem como circunstâncias pré-definidas pelo pintor informal/patrão. Mesmo no caso do pintor informal ser um trabalhador autônomo ${ }^{11}$, isto é, patrão/empregado, esse ainda não possui total autonomia no âmbito do processo de produção do serviço de pintura, na medida em que tem liberdade apenas para organizar o trabalho, cabendo ao cliente definir as cores da construção, o tipo de pintura do imóvel e outras coisas, o que faz dele um suposto "patrão" temporário que restringe a sua autonomia.

No entanto, em termos de poder de negociação de melhores condições de trabalho, esse saber demonstra-se ineficiente já que não permite superar a precarização

\footnotetext{
11 “O trabalhador autônomo é a pessoa física que presta serviço habitualmente por conta própria a uma ou mais de uma pessoa, assumindo os riscos de sua atividade econômica” (MARTINS apud BOSCO, 2006, p. 90).
} 
das relações de trabalho do pintor informal na construção civil de Abaeté e, consequentemente se afirmar no cotidiano social como um mecanismo de pressão e poder na luta por melhores condições de trabalho e vida diante das mudanças no mundo do trabalho.

\section{Formas de Participação na Produção do Serviço de Pintura}

Dos pintores informais entrevistados $90 \%$ participam da produção do serviço de pintura como trabalhador ao venderem a sua força de trabalho para um cliente ou pintor informal/patrão. Enquanto $10 \%$ dos entrevistados participam como pintor informal/patrão que além de administrar os seus negócios, também atua de forma direta na produção.

Os pintores informais que vendem a sua força de trabalho a um pintor informal/patrão além de estarem a margem do sistema de proteção social e previdenciário, uma vez na informalidade, também estão sujeitos à exploração capitalista, visto que o pintor informal/patrão se apropria do trabalho excedente ou mais-valia produzida pelo pintor informal/trabalhador. No entanto, mesmo extraindo mais-valia, substrato do lucro capitalista, do pintor informal/trabalhador, que geralmente é alguém da família como veremos mais na frente, não consegue acumular capital já que "[...] vende seus serviços ou mercadorias e recebe um montante de dinheiro que é utilizado, principalmente, para consumo individual e familiar e para manutenção da atividade econômica" (CACCIAMALLI, 1983, p. 31).

Por outro lado, esses pintores, que representam $10 \%$ do total dos entrevistados, por possuírem alguns meios de produção, participam na produção do serviço de pintura como patrão/empregado explorando um ajudante ou a mão-de-obra familiar. Nesse sentido, Cacciamalli (1983) afirma que o produtor informal é o dono dos instrumentos de trabalho ou do estoque de bens necessários para a realização do seu trabalho e insere-se na produção como patrão/empregado. O fato de explorar seus ajudantes via apropriação do trabalho excedente possibilita-Ihe auferir uma renda mensal um pouco maior como veremos a seguir.

Porém, não se pode afirmar que somente a posse de instrumentos de trabalho necessários para o seu trabalho, ou seja, as ferramentas como rolo de lã, pincel, 
desempenadeira de aço, escova de aço, escada, compressor e outras sejam suficientes para o pintor informal tornar-se um patrão e empregar alguém da família ou um ajudante e, por conseqüência, explorá-lo. Esses são necessários no processo de produção do serviço de pintura, mas somente enquanto meios utilizados pelo trabalhador para atuar sobre determinada matéria-prima ${ }^{12}$ (casa, prédio, e outras construções) produzindo determinado produto final, isto é, determinada construção pintada. Sem a matéria-prima são apenas ferramentas que nada produzem ou transformam.

A matéria-prima, no entanto, pertence a outro, isto é, um cliente, e só lhe aparece quando esse contrata o serviço de pintura, já que o pintor informal/patrão vende no mercado sua força de trabalho disfarçada em forma de prestação de serviço. Seguindo esse raciocínio, a posição seja de explorador ou explorado, ocupado pelo pintor informal dentro do processo de produção do serviço de pintura na construção civil dependerá muito mais da contratação do serviço por determinado cliente, ou seja, da capacidade do pintor informal de obter e manter certa clientela, que necessariamente da posse das ferramentas de trabalho que, geralmente, apresenta valor pecuniário irrisório. Por isso, todo pintor informal que vende a sua força de trabalho para outro pintor informal é um patrão/empregado em potencial e, nesse sentido, todo patrão/empregado é um trabalhador em potencial.

Contudo, o simples fato do pintor informal/patrão possuir algumas ferramentas e uma clientela que permite, algumas vezes, explorar um ajudante não é suficiente para fazer dele um capitalista ou microempresário ${ }^{13}$ como quer a mídia acrítica, pois o fato de possuir alguns meios de produção "[...] que the possibilita oferecer ocupações a outras pessoas, fazendo dele um empregador, não faz necessariamente daqueles meios capital, nem do sujeito um capitalista." (TAVARES, 2004, p. 31).

O mito do microempresário, nessa linha de pensamento, não suporta uma analise crítica, mesmo que no cotidiano do pintor informal um pouco de flexibilidade no horário de trabalho juntamente com o fato de receber pelo serviço prestado, e a quase

\footnotetext{
${ }^{12}$ Conforme Marx (1994) o processo de trabalho pelo qual o homem produz valores-de-uso é constituído por três elementos: "[...] 1 a atividade adequada a um fim, isto é, o próprio trabalho; 2 matéria a que se aplica o trabalho, o objeto de trabalho; 3 os meios de trabalho, o instrumento de trabalho" (MARX, 1994, p. 202).

${ }^{13}$ Conforme Tavares (2004, p. 111) “[...] embora, se dê destaque às experiências bem sucedidas, não se pode esconder que, no Brasil, aproximadamente $50 \%$ dos pequenos negócios fecham suas portas antes de completar um ano de vida, demonstrando que a prática nega o otimismo do discurso."
} 
inexistência da figura do patrão, engendre a fantasia de independência e liberdade, substrato do sentimento de microempresário à margem da exploração capitalista. $\mathrm{Na}$ verdade, o pintor informal/patrão conserva a sua condição operária ao necessitar vender a sua força de trabalho no mercado, embora mascarada em forma de prestação de serviço. Além disso, às vezes o seu trabalho se estende aos feriados e domingos, bem como está sujeito à exploração capitalista quando contratado por uma empresa do setor da construção civil. Tudo isso faz dele um trabalhador, mesmo que o processo de alienação o faça criar uma auto-imagem enquanto microempresário, negando a sua própria condição.

\section{Renda}

Conforme a pesquisa, $90 \%$ dos pintores entrevistados possuem uma renda média de 2 (dois) salários ${ }^{14}$ mínimos por mês, enquanto $10 \%$ possuem uma renda média acima de 2 (dois) salários. Essa diferença de renda reflete a forma pela qual o pintor informal participa na produção do serviço de pintura. Os primeiros por participarem como pintor informal/trabalhador granjeiam uma renda menor que os segundos, que por sua vez participam na produção do serviço de pintura como pintor informal/patrão, por isso se apropriam de uma renda maior, já que extraem dos primeiros mais-valia.

O pintor informal/trabalhador não apresenta renda fixa, no sentido de salário mensal fixo, sendo sua renda calculada com base no sistema valor/dia, isto é, recebe um determinado valor por dia trabalhado. Desta forma, o suposto salário variável e instável depende do numero de dias trabalhado por mês. Isso diz respeito somente à relação em que o pintor informal vende a sua força de trabalho a outro pintor designado patrão/empregado ou a um cliente. Na primeira situação o valor do dia/trabalho, geralmente, é menor, uma vez que o pintor/trabalhador não tem despesas com ferramentas que cabe ao pintor informal/patrão providenciar. Já na segunda situação o valor dia/trabalho tende a ser maior por incluir despesas com ferramentas, já que vende a sua força de trabalho metamorfoseada como prestação de serviço a um cliente. Esse valor depende também da capacidade de

\footnotetext{
${ }^{14}$ É importante ressaltar que os serviços de pintura não são remunerados com base no sistema de assalariamento, mesmo que esse de certa forma exerça influência no seu valor, assim sendo utilizamos o termo salário somente como parâmetro para medir a renda dos pintores informais.
} 
negociação junto a seu respectivo "patrão", bem como do grau de conhecimento acerca da produção do serviço de pintura.

Embora, o pintor informal/trabalhador receba a soma do valor dia/trabalho, geralmente a cada final de semana, tal fato cria nele a ilusão de que o pintor informal/patrão lhe paga o valor real do seu trabalho, na medida em que sua remuneração acontece posterior à efetuação do trabalho, por isso "[...] imagina que o valor ou preço de sua força de trabalho é o preço ou o valor do seu próprio trabalho" (MARX, 1978, p. 84) e, por conseqüência, acredita que o lucro do pintor informal/patrão decorre da capacidade de negociar determinada empreitada ou serviço de pintura por um valor superior ao valor necessário para executá-lo. Essa mistificação das relações de trabalho, presente também no setor informal, obscurece a exploração capitalista.

Nos casos em que o pintor informal/patrão trabalha por empreita, o valor da prestação do serviço de pintura é previamente combinado com o cliente, mas esse fato não possibilita ao mesmo uma renda fixa. Nesse sentido, conforme Cacciamalli (1983) o valor de determinado serviço prestado no setor informal, nos centros urbanos, "[...] é fixado em função dos custos de serviço - materiais, mão-de-obra, tempo, transporte - do nível de renda do cliente, da potencialidade do cliente em relação a serviços futuros, da relação pessoal e do conhecimento que o cliente tem sobre a natureza do serviço" (CACCIAMALLI, 1983, p. 48). A autora, também, salienta que quando os serviços se destinam aos indivíduos de baixa renda, o preço é fixado pelo vendedor num patamar mínimo tolerável. Enquanto quando os serviços se destinam aos segmentos com alta renda "[...] o preço é fixado por meio de barganha e dos fatores mencionados" (CACCIAMALLI, 1983, p. 48) acima.

Todos esses fatores influenciam no valor do serviço de pintura na construção civil de Abaeté, contudo o fator tempo ${ }^{15}$ constitui o maior determinante no valor do serviço. Além disso, na construção civil do município de Abaeté, a concorrência também atua como um dos fatores que determina o valor do serviço de pintura prestado. Geralmente,

\footnotetext{
15 Nas palavras de Marx (1978, p. 76-77), o valor de uma mercadoria é determinado: “[...] pela [...] quantidade de trabalho necessário para produzir essa mercadoria num dado estado social e sob determinadas condições sociais médias de produção, com uma dada intensidade social média e com uma destreza média no trabalho que se emprega."
} 
a concorrência e a competitividade entre os próprios pintores informais tendem a baixar o preço médio do serviço de pintura no município.

\section{Grau de parentesco}

Quase a metade (40\%) dos pintores informais entrevistados possui algum grau de parentesco com o seu patrão/empregado. De acordo com Cacciamalli (1983, p. 31) “o produtor informal emprega a si mesmo podendo, também, explorar a mão-de-obra familiar ou de ajudantes." Desta maneira, as relações familiares existentes entre o trabalhador/família e o seu patrão/ família são substituídas pelas relações de exploração capitalista, na medida em que os interesses e desejos do patrão/família estão condicionados à racionalidade capitalista, isto é, exploração, lucro e acumulação. Mesmo que seja pai ou irmão de determinado pintor/trabalhador irá explorá-lo "[...] já que as leis objetivas do sistema capitalista são inflexíveis: ou a exploração dos trabalhadores ou a morte do empresário; não há alternativa." (HARNECKER, 1971, p. 61).

Tais relações familiares facilitam a introdução do indivíduo no setor informal, uma vez que algum membro da família atuando como produtor informal do serviço de pintura na construção civil poderá empregar algum parente desempregado. Também, coopera para a transmissão informal dos conhecimentos de pintura, visto que os produtores informais do serviço de pintura dão preferência a alguém da família na hora de empregar um ajudante.

Assim, entre os entrevistados, em alguns casos, o saber profissional do pintor foi passado de irmão para irmão ou de pai para filho. Porém, por outro lado, a veemência dessas relações familiares no âmbito do processo de produção do serviço de pintura na construção civil de Abaeté constitui-se um obstáculo ao acesso ao conhecimento do processo de pintura e, por conseguinte, ao acesso à atividade aqueles que não são parentes de um pintor.

Esse grau de parentesco e, consequentemente, a inexistência de "[...] vínculo impessoal ou meramente de mercado entre os que trabalham [...]" (CACCIAMALLI, 1983, p. 32) no setor informal, coopera ou facilita a proliferação da irregularidade, da fraude 
previdenciária e da precarização das relações de trabalho ${ }^{16}$, como veremos adiante, já que as relações de trabalho são permeadas por relações familiares e afetivas que se misturam e sobrepõem às relações meramente de trabalho sem, no entanto, superá-las. Nesse sentido, a solidariedade familiar, os laços sócio-afetivos e os vínculos familiares corroboram para que se perpetuem as condições de precarização do trabalho do pintor informal, pois sufocam as possibilidades de contestação de tal situação na medida em que qualquer contestação do pintor informal/trabalhador será considerada pela família como uma contestação dos próprios laços afetivos e vínculos familiares.

No entanto, não podemos aqui desconsiderar que a solidariedade familiar constitui algo positivo na vida social do indivíduo, porém a solidariedade familiar no sentido de algum produtor informal do serviço de pintura empregar parente desempregado não constitui uma solidariedade plena, mas restrita. Tal solidariedade vai somente até o ponto de empregar um parente para ajudá-lo em termos econômicos, a partir desse ponto a solidariedade familiar se transforma em extração de sobre-trabalho. Portanto, neste caso, na sociedade capitalista, a solidariedade familiar só pode ser restrita, a menos que os membros da família trabalhem em forma de cooperativa e, conseqüentemente, estabeleçam relações sociais de produção pautadas na propriedade coletiva e cooperação mutua.

\section{Representação sindical}

Nenhum pintor informal entrevistado participa de algum sindicato da categoria. Eles vêem o seu poder de negociação para reivindicar melhores condições de trabalho reduzido ou fragilizado por não participarem de um sindicato que canalize e fortaleça os interesses da classe. Tal fato constitui uma das dimensões do quadro de precarização do trabalho no qual o pintor informal do município de Abaeté se insere em condições precárias no mundo do trabalho, tendo seu trabalho marcado pela violação de direitos, pela falta de expressão sindical, como também pela falta de proteção social e previdenciária.

\footnotetext{
${ }^{16}$ Embora, “[...] a pequena e microempresas têm um papel fundamental na difusão da ilegalidade, da irregularidade, da corrupção e da precarização das condições de trabalho de parcela expressiva da população brasileira" (MALAGUTI apud TAVARES, 2004, p.43). Essa, na contemporaneidade, aparece no discurso dos empresários e na mídia acrítica como o reino da liberdade e da autonomia.
} 
A pesquisa aponta a incapacidade dos sindicatos herdeiros do fordismo (ANTUNES, 2000) em aglutinar trabalhadores informais. E conseqüentemente, isso coopera de certa forma para que os sindicatos da categoria e por último toda classe trabalhadora perca parte ou quase todo o seu poder de negociação e mobilização social frente ao capital. Isso se desdobra em posturas defensivas frente às investidas do capital para recuperar as altas taxas de lucro dos "anos de ouro".

Nesse sentido, conforme Antunes (2000, p. 43) os sindicatos estão se distanciando “[...] crescentemente do sindicalismo e dos movimentos sociais classistas dos anos 60/70, que propugnavam pelo controle social da produção, aderindo ao acrítico sindicalismo de participação e de negociação, que em geral aceita a ordem do capital e do mercado [...]", isso não só leva ao abandono das "[...] perspectivas que se inseriam em ações mais globais que visavam à emancipação do trabalho, a luta pelo socialismo e pela emancipação do gênero humano [...]", mas na "[...] aceitação também acrítica da social democratização, ou o que é ainda mais perverso, debatendo no universo da agenda e do ideário neoliberal." (ANTUNES, 2000, p. 43).

Diante dessa crise sindical perceptível na pesquisa, para Antunes (2000, p. 171) o maior desafio da classe que vive do trabalho nessa virada do século XX para o XXI é "[...] soldar os laços de pertencimentos de classes existentes entre os diversos seguimentos que compreendem o mundo do trabalho [...]" procurando articular os segmentos que trabalham no "centro" do processo de criação de valores de troca e "[...] os segmentos que estão mais à margem do processo produtivo, mas que, pelas condições precárias em que se encontram, se constituem em contingentes sociais potencialmente rebeldes diante do capital e suas formas de (des) socialização." (ANTUNES, 2000, p. 171).

\section{Instabilidade do serviço de pintura}

Conforme a pesquisa, 70\% dos entrevistados trabalha em média de 11 (onze) a 20 (vinte) dias por mês, enquanto os $30 \%$ restante trabalham em média mais de 20 (vinte) dias. Nesse sentido, Cacciamalli (1983, p. 32) salienta que o processo da produção informal é descontínuo ou intermitente seja por características do próprio produtor, da atividade ou mercado. Quanto a isso Tiago, um dos entrevistados, que trabalha a oito anos na área, comenta que: "[...] tem umas época que é complicado para trabalhar como 
nas épocas das chuvas [...] tem vez que tem muito serviço que você num dá conta de fazer o serviço mas tem época que num tem é nada [...]".

Assim, o pintor informal tem trabalho ou não de acordo com os períodos de chuva que podem impossibilitar o seu serviço ou flutuações do mercado, isto é, em épocas de desenvolvimento econômico, com o aumento das demandas do mercado em expansão, não Ihe faltam clientes e, por conseqüência, serviço. Enquanto em épocas de recessão econômica acontece o oposto. É justamente essa flexibilidade que permite pensar o pintor informal como excluído flexível, incluído de forma precária no mercado de trabalho em uma ocasião e excluído dele em outra, conforme as oscilações do mercado.

Por isso, a relação da atividade do pintor informal com o mercado formal existe, não só em termos de oferta de serviço, mas também em termos de subordinação. Nessa perspectiva, a teoria da subordinação de cunho marxista, que teve sua gênese nos anos 1980, afirma que o setor formal e informal, dentro da sociedade capitalista, estabelece uma relação de interdependência e subordinação. "Cada pólo da relação se beneficia e depende do outro, mas de maneira diversa. A dependência é complexa e fortemente favorável à hegemonia capitalista" (GERRY apud CACCIAMALI, 1983, p. 26).

O setor informal, nesse sentido, é uma esfera econômica subordinada à lógica capitalista (CACCIAMALI, 1983, p. 27), por isso “[...] a subordinação dos movimentos das atividades informais aos das formais provoca constantemente a destruição e recriação das primeiras" de modo que o setor informal ocupa os espaços econômicos não ocupados pelo capital se adaptando ao nível de produtividade média social, tempo de trabalho e as relações de mercado que permeiam determinado espaço econômico. Nessa linha de pensamento, Souza (apud TAVARES, 2004, p. 38) afirma que "[...] essa subordinação admite vários graus, podendo ir desde o simples preenchimento de um espaço no mercado sem que haja qualquer relação de exploração ou extração de excedente, até formas mais diretas de subordinação onde estas relações existem."

Nessa linha de raciocínio, a produção informal dos serviços de pintura na construção civil do município de Abaeté "[...] ocupa os espaços econômicos, os interstícios, não ocupados pelas formas de organização da produção capitalista [...]" (CACCIAMALLI, 1983, p. 31), ou melhor, a quase inexistência de empresas capitalistas no ramo econômico de pintura na construção civil da cidade possibilita que as formas de 
produção informal do serviço de pintura ocupem esse espaço econômico. Nesse caso, a subordinação ao modo de produção capitalista acontece via preenchimento do espaço no mercado, contudo, raras vezes observam-se relações de exploração via terceirização do serviço de pintura a médias e pequenas empresas de pintura ou pintores informais/patrão. Um exemplo disso aconteceu na construção de duas quadras esportivas no município e na reforma de agência do Banco do Brasil, em ambos os casos grandes empresas terceirizaram o serviço de pintura para pequenas empresas prestadoras de serviço de pintura no município.

Nesse caso, observa-se o fenômeno que Tavares (2004) chama de a "nova informalidade" oriunda do fenômeno da terceirização que permite ao capital transferir às pequenas unidades produtivas encargos trabalhistas e sociais, além dos riscos da produção, aumentando assim os seus lucros. A "nova informalidade" funcional ao modo de produção capitalista atende as necessidades do novo rearranjo capitalista, na medida em que o "[...] capital flexível necessita cada vez menos do trabalho estável e cada vez mais do trabalho parcial ou part-time, terceirizado, que são, em escala crescente, parte constitutiva do processo de produção capitalista" (ANTUNES, 2000, p. 10).

A "nova informalidade", conforme Tavares (2004) é constituída, principalmente, por cooperativas, trabalho domiciliar, pequenas e microempresas que cumprem funções externalizadas pelas grandes empresas por meio de um "[...] contrato de terceirização, que torna a grande empresa cliente e a pequena fornecedora, a relação comercial substitui a trabalhista, criando a ilusão de que agora as duas são agentes econômicos iguais [...]" (TAVARES, 2004, p.186). Assim, o fim da exploração de classe seria somente uma questão de tempo, uma vez que todos seriam capitalistas e, consequentemente se relacionariam no mercado como iguais, já que os trabalhadores venderiam no mercado o produto do seu trabalho, ao invés de sua força de trabalho.

Tal idéia irreal difundida, principalmente pela mídia acrítica, mascara a relação capital/trabalho e obscurece a extração de sobre-trabalho ao fazer apologia à pequena e microempresa como sinônima de autonomia e independência em contraposição a exploração capitalista. 


\section{Carteira de trabalho}

Dos pintores entrevistados $60 \%$ nunca tiveram a sua carteira de trabalho assinada nessa categoria profissional, enquanto, por outro lado $40 \%$ deles já tiveram em algum período a carteira de trabalho assinada como pintor de paredes.

No primeiro caso há vários motivos que desencadeiam a não observância à legislação trabalhista por parte do patrão/empregado. Entre esses podemos destacar a insuficiência de recursos econômicos do patrão/empregado para cumprir a lei. Nessa situação, devemos considerar que o patrão/empregado também é um pintor informal e pelo fato de possuir parcos meios de produção, "que lhe permite oferecer ocupações a outras pessoas, fazendo dele um empregador, não faz necessariamente daqueles meios capital, nem do sujeito um capitalista" (TAVARES, 2004, p. 31). Com isso, não quero afirmar que os encargos trabalhistas fomentam a informalidade, mas simplesmente que $o$ pintor informal/patrão não pode ser considerado um capitalista ou empresário.

Geralmente, o pintor informal/patrão não possui firma registrada exercendo sua atividade na irregularidade, esse fato o impossibilita de assinar a carteira de trabalho do seu ajudante. Outro motivo para o não comprimento da legislação trabalhista nasce da necessidade do pintor informal/patrão reduzir os custos da produção a fim de obter maiores lucros. É importante destacar que embora não seja um capitalista, está sujeito, mesmo que em escala menor, às leis do mercado sob a direção da racionalidade capitalista.

Portanto, o pintor informal/patrão para aumentar o lucro necessita aumentar a produtividade e reduzir os custos da produção, isso significa pintar mais obras em menos tempo por meio da intensificação do trabalho, reduzindo o tempo de trabalho ocioso, e diminuir gastos da produção não pagando encargos trabalhistas e vigiando o pintor informal para poupar "[...] o instrumento de trabalho, de modo que só se gaste deles o que for imprescindível à execução do trabalho" (MARX, 1994, p. 269). Enfim, a forma como se insere no mercado de trabalho e as suas condições de vida e trabalho não diferem muito das condições do seu ajudante, já que ambos são pintores informais e, consequentemente, estão a margem do sistema de proteção social e previdenciário.

No que se refere aos entrevistados que já tiveram alguma vez a carteira de trabalho assinada na categoria, alguns depoimentos são esclarecedores para a compreensão do 
que seria essa suposta formalização. Tiago relata que "[...] agora assinaram minha carteira, mas com o acordo de não ter nenhum direito só porque uma firma estava precisando de trabalhadores de carteira assinada". E coloca ironicamente que "agora me considero como cidadão até veio um cartãozinho (cartão cidadão)". Mateus destaca que após a conclusão do serviço "[...] só recebe o seguro-desemprego". Não iremos transcrever todos os depoimentos, pois não só consideramos desnecessário, visto que todos são semelhantes, mas também seria exaustivo. Portanto, basta colocar que dos $40 \%$ dos entrevistados que em algum momento tiveram a carteira de trabalho assinada nenhum deles teve todos os seus direitos trabalhistas resguardados.

Através dos depoimentos, fica evidente a existência de um contrato de trabalho paralelo ao contrato de trabalho legal expresso na carteira de trabalho. Esse "contrato paralelo" se fundamenta no descumprimento quase total do preconizado pela legislação trabalhista. A maioria desses casos ocorre em grandes construções como, por exemplo, edifícios, onde há maior possibilidade de fiscalização por parte do Ministério do Trabalho. Por isso, o dono da construção, devido ao risco da obra ser embargada, ser multado, na ocorrência de acidentes no canteiro de obras que engendram indenizações entre outros motivos, assina a carteira de trabalho do pintor informal/patrão e de seus ajudantes ou pintor informal/trabalhador, mas antes disso negocia os termos de um "contrato paralelo". Essas regras estabelecem que o empregador não irá custear todos os encargos trabalhistas tais como férias, 13ำ salário e a multa de rescisão de contrato, assim como em alguns casos os encargos sociais e trabalhistas ficam todos a cargo do trabalhador.

O pintor informal aceita tal "contrato paralelo" pelos seguintes motivos: em primeiro lugar acredita que não tem nada a perder somente a ganhar, uma vez que esse contrato aparece como uma possibilidade de inclusão social, mesmo que temporária, no sistema de proteção social e previdenciária, desde que desista de parte dos seus direitos enquanto trabalhador. Em segundo lugar, a não adesão a esse contrato significa a não contratação. Em terceiro lugar, enquanto trabalhador necessita vender a sua força de trabalho como qualquer outro trabalhador para garantir a sua reprodução existencial, assim sendo, se não a vender nessas condições impostas pelo dono da construção (empregador) a venderá em condições, talvez, até mais precárias. E por último, concorda com os termos do "contrato paralelo" pela conviç̧ão de que irá receber futuramente o 
seguro-desemprego e o Fundo de Garantia por Tempo de Serviço (FGTS) benefícios, aliás, direitos oriundos da assinatura da carteira de trabalho.

Na verdade, esse "contrato paralelo" consubstancia uma forma informal e ilegal de flexibilizar as relações trabalhistas ditas onerosas ${ }^{17}$ para o capital. Ainda, nessa concepção de flexibilização, Oliveira (2010), em um artigo intitulado A Falência do Emprego e o Advento do Trabalho informal, defende "[...] a reforma trabalhista que desonere tanto a contratação quanto a dispensa de empregados [...]" e a criação de medidas fiscais e tributárias que incentivem a contratação como uma forma de combater a informalidade no Brasil. Para o autor, "[...] não é imprescindível uma carteira de trabalho assinada, mas, sim, a condição de trabalhar, respeitados os requisitos mínimos de saúde, segurança e bem-estar [...]" e ainda diz que: "[...] não se trata, pois, de excluir tais direitos, mas, sim, de flexibilizá-los à conveniência de patrões e empregados com vantagens para ambos." É justamente, isso que o "contrato paralelo" entre empregador e pintor informal faz só que ao invés de vantagens para ambos o que se percebe na prática é a desoneração para o empregador e a precarização das condições de trabalho para o pintor informal.

Em resumo, a assinatura da carteira de trabalho do pintor na construção civil da cidade de Abaeté/MG não significa o cumprimento da legislação trabalhista, pelo contrário, é uma forma de mascarar a dura realidade vivenciada pelos pintores. Embora, o pintor informal possa recorrer ao Poder Judiciário para fazer valer os seus direitos, raramente, isso acontece por medo de retaliações futuras no sentido de não the oferecerem mais serviço na construção civil, denegrirem a sua imagem profissional, ou ainda por possuir algum grau de parentesco com o pintor informal/patrão como vimos.

\section{Previdência social}

Dos entrevistados apenas $10 \%$ dos pintores informais contribui para a previdência social como trabalhador autônomo, ou melhor, contribuinte individual o que the assegura uma proteção social parcial, uma vez que a contribuição nessa

17 Conforme lamamoto (2000, p. 45) “Confunde-se o que é custo salarial - envolvendo obrigações trabalhistas, $13^{\circ}$ salário, férias, fundo de garantia, rescisão contratual, descanso semanal remunerado; enfim benefícios associados ao trabalho já realizado que favorecem diretamente o trabalhador e representam conquistas sociais trabalhistas já consolidadas, com os custos, de fato, sociais que estão embutidos na folha de salário." 
modalidade não gera direito a seguro-desemprego, salário-família, auxilio-acidente e outros benéficos previdenciários. Enquanto $90 \%$ dos pintores informais não contribuem e, por isso se encontram a margem do nosso sistema previdenciário fundamentado na contribuição, ou dito de outra forma, para o cidadão brasileiro ter direito aos benefícios previdenciários é requisito básico a contribuição para esse sistema, salvo o benefício de prestação continuado da assistência social (BPC), destinado aos idosos com sessenta e cinco (65) anos ou mais e a pessoa com deficiência que preenchem os requisitos legais para tal. Contudo, apesar desse benefício ser operacionalizado pelo Instituto Nacional de Seguro Social (INSS) os recursos para custeio são provenientes da política de assistência social. Assim sendo, temos de um lado a previdência social para os que contribuem e, de outro lado a assistência social, enquanto política publica, para os que não contribuem.

O fato da maioria dos pintores informais não contribuírem para o sistema previdenciário os deixa desprotegidos dos riscos sociais e pessoais como acidentes, doenças, velhice e outros fatores inerentes ao ciclo da vida que o impossibilite durante um determinado tempo ou durante o resto da vida a exercer o seu ofício. A falta de proteção social também atinge a esfera familiar do pintor informal, já que em caso de doença, idade avançada, desemprego, a sua família poderá sofrer desde a queda na qualidade de vida até privações materiais como, por exemplo, falta de alimentos de primeira necessidade. Tudo isso desloca o pintor informal da esfera da cidadania para a esfera da negação da cidadania quando se leva em conta que não se exercita na vida social meia cidadania. É importante destacar que esse estudo não investigou as possíveis causas para a não contribuição dos pintores informais para o sistema previdenciário.

Esse quadro também colabora para aumentar o déficit da previdência social brasileira que "[...] foi estimado em cerca de R\$ 75 bilhões [...]" (PASTORE, 2010) em 2004. Para amenizar esse quadro no sentido de aumentar a arrecadação fiscal e estender a proteção social àqueles que se encontram na informalidade, o governo brasileiro criou o Programa Simples, em 1997, que reduz aproximadamente em $19 \%$ os encargos trabalhistas com o intuito de incentivar a formalização das relações de trabalho informal oriundas das pequenas e medias empresa e o programa Micro Empreendedor Individual 
(MEI) ${ }^{18}$, em 2008, com a intenção de formalizar a informalidade advinda do trabalho autônomo. Essas duas propostas de combate à informalidade flexibilizam as relações de trabalho buscando adaptá-las à nova ordem do capital e, ao mesmo tempo, tentam incluir aqueles excluídos do sistema previdenciário e aumentar a arrecadação de impostos, ao invés de configurar o sistema previdenciário brasileiro em base não contributiva de forma direta.

Contudo, esse modelo previdenciário, não só reproduz a monstruosa desigualdade social brasileira, na medida em que o valor dos benefícios previdenciários é proporcional ao valor da contribuição, mas também a precarização das relações de trabalho ao contribuir, de certa forma, para que os trabalhadores informais permaneçam à margem do sistema de proteção social e previdenciário. Aos excluídos desse sistema resta a assistência social enquanto política pública não contributiva que visa assegurar um mínimo social por meio de um "[...] conjunto integrado de ações de iniciativa pública e da sociedade, para garantir o atendimento às necessidades básicas" (BRASIL, 1993) a "[...] quem dela necessitar [...]" (BRASIL, 1988).

\section{Considerações Finais}

No novo (e precário) mundo do trabalho (ALVES, 1999, p. 137) criado pelas políticas neoliberais e pelas mudanças no mundo do trabalho, a expansão da informalidade adquire destaque em meio à precarização das relações de trabalho. Em resposta à expansão da informalidade no Brasil surgem duas propostas de combate. A primeira, de cunho neoliberal, advoga como solução para o problema da informalidade a flexibilização das relações de trabalho, uma vez que a rigidez das leis trabalhistas colabora para o aumento da informalidade. Isso romperia a linha tênue que separa, na atualidade, os trabalhadores formais dos trabalhadores informais precarizando as relações de trabalho.

Nesse sentido, na construção civil de Abaeté os "contratos paralelos" presentes na atividade do pintor informal evidenciam de forma clara como seria na prática a flexibilização das leis trabalhistas. Tal medida significaria para a classe capitalista vantagens em termos de aumento de competividade, desoneração de encargos

\footnotetext{
${ }_{18}$ Para maiores informações referentes ao programa MEI acessar O PORTAL DO EMPREENDEDOR. Disponível em: <http://www.portaldoempreendedor.gov.br>.
} 
trabalhistas, redução dos custos de produção, enfim, elevação da taxa media de lucro. Enquanto para o trabalhador representaria maior instabilidade no emprego, intensificação do trabalho, precarização do trabalho, enfim, condições de trabalho semelhantes a do pintor informal.

A segunda, por outro lado, busca a legitimação social da informalidade na sociedade, via legalização. Nesse caso, o Estado estimula a formalização do setor informal por meio de políticas públicas e a criação de "[...] mecanismos legais que permitam a produção capitalista a maior utilização do trabalho informal” (TAVARES, 2004, p. 20) com o propósito de tornar menos visível o quadro de pobreza acentuado pelo Programa de Ajuste Econômico (PAE) pautado no ideário neoliberal, bem como aumentar a arrecadação de impostos.

Ao deslocarem a questão da informalidade e do desemprego da esfera da produção para a esfera da legalidade e das políticas publicas obscurecem e mistificam as bases materiais do setor informal distorcendo a realidade e disseminando a falsa crença "[...] de que o mercado de trabalho quanto mais desregulado for, mais favorável será a elevação do nível geral de emprego" (POCHAMANN apud PINTO, 2007, p. 55). São absurdas tais afirmações, pois esses problemas são de ordem econômica e estrutural e, portanto, só podem ser esclarecidos a partir da esfera da produção, assim como a solução concreta para a precarização do trabalho só pode ser pensada em uma sociedade para além do capital, pois demais tentativas dentro da lógica capitalista não passam de meros reparos paliativos.

A precarização das relações de trabalho decorrente das mudanças no mundo do trabalho repercutiu basicamente de três formas no Serviço Social: a primeira diz respeito ao desafio posto ao Serviço Social de dar respostas concretas às novas demandas emergentes da classe trabalhadora e a consolidação do projeto-ético-político do Serviço Social, uma vez que a classe trabalhadora ficou mais heterogênea, fragmentada e complexa. A segunda se refere à precarização das relações de trabalho do assistente social na atualidade. E a última, diz respeito ao processo de fomento da informalidade pelo Serviço Social como ação complementar ou endógena da política de assistência social, na medida em que as atividades informais de restrita sobrevivência foram deslocadas do âmbito econômico para as políticas de assistência social e os demais 
trabalhos por conta própria estão sendo encarados como empresa (TAVARES, 2004, p. 34).

Tal processo pode ser ilustrado com as ações de inclusão produtiva que adquirem forma e materialidade através dos cursos de capacitação de manicure, cuidador de idoso, pedreiro, salgados e outros ofertados e executados nos Centros de Referência de Assistência Social (CRAS) no âmbito do Sistema Único de Assistência (SUAS) gerido, principalmente, por assistentes sociais.

Desta forma, o Serviço Social no âmbito da política de assistência social, em resposta ao desemprego estrutural estimula a "[...] potencialidade do 'setor informal' como fonte de emprego a baixo custo, desde que amparados por políticas governamentais" (TAVARES, 2004, p. 32), no entanto, desconsidera a qualidade desses empregos e as condições precárias em que se realizam valorizando somente a criação de ocupações aos excluídos do mercado de trabalho.

Para finalizar queremos destacar que não se pretende com esse estudo diante da precarização do trabalho expresso na informalidade do pintor na construção civil passar a mensagem de que o trabalho assalariado ou trabalho formal seja a forma ideal de inserção no mercado de trabalho, pelo contrário, queremos reafirmar que a forma ideal da objetivação da atividade genérica humana só pode ser pensada em uma sociedade para além do capital.

\section{Referências}

ALVES, Giovanni. Cap.VI e VII. Trabalho e Mundialização do Capital. A nova Degradação do Trabalho na Era da Globalização. Editora Práxis, 1999.

ANTUNES, Ricardo. Adeus ao trabalho? Ensaio sobre as metamorfoses e a centralidade do mundo do trabalho. 7 ed. São Paulo: Cortez, Campinas. Universidade Estadual de Campinas, 2000.

Os sentidos do trabalho. São Paulo: Tempo, 2001.

BOSCO, Carlos Alberto. Trabalho informal: realidade ou relação de emprego fraudulenta? 4. ed. Curitiba: Juruá, 2006.

BRASIL. Constituição da República Federativa do Brasil. Brasília: Senado Federal, 1988. 
BRASIL. Lei Orgânica da Assistência Social, n.8742. Dispõe sobre a organização da Assistência Social e dá outras providências. 7 de dezembro de 1993, publicada no DOU de 8 de dezembro de 1993.

CACCIAMALI, Maria Cristina. Setor Informal Urbano e Formas de Participação na Produção. Tese de Doutorado apresentada à Faculdade de Economia, Administração e Contabilidade da Universidade de São Paulo. São Paulo: IPE, Série Ensaios Econômicos, n.26, 1983.

HARNECKER, Marta. Os Conceitos Elementais do Materialismo Histórico. 6.ed. Rio de Janeiro: Global, 1971.

IAMAMOTO,Marilda Villela. O serviço social na contemporaneidade: trabalho e formação profissional. 3 ed. São Paulo, Cortez, 2000.

MARX, Karl.Manuscritos econômicos-filosôficos e outros textos. 2.ed. São Paulo: Abril, 1978.

.Cap. item 4. O fetichismo da mercadoria: seu segredo; Cap.V Processo de trabalho e processo de produzir mais valia. In: O capital. São Paulo: Betrand Brasil, 1994. p. 79-93; p. 201-223.

.Trabalho estranhado e propriedade privada; A relação da propriedade privada; Propriedade privada e trabalho. In: Manuscritos econômico-filosóficos. São Paulo: Boitempo, 2004.

MIRANDA, Dalton Fernando; NOGUEIRA, Guaracy de Castro (Org.). Centro-Oeste Mineiro: história e cultura. Itaúna: Totem Centro Gerador de Cultura; Instituto Maria de Castro Nogueira, 2008, p.23-26

OLIVEIRA, Fernando Antônio Matos. A Falência do Emprego e o Advento do Trabalho Informal. Disponível em: <

http://www.conpedi.org.br/manaus/arquivos/anais/salvador/fernando_antonio_matos_de_ oliveira.pdf>. Acesso em 16 jun.2010.

PASTORE, José. Informalidade: Estragos e Soluções. Disponível em:

<http://www.josepastore.com.br/artigos/ti/ti_014.htm>. Acesso em 16 jun. 2010.

PINTO, Geraldo Augusto. A organização do trabalho no século 20 taylorismo, fordismo e toyotismo. 1.ed. São Paulo: Expressão, 2007.

SADER, Emir (Org.). Pós-neoliberalismo: as políticas sociais e o estado democrático, Rio de Janeiro: Paz e Terra, 1995.

TAVARES, Maria Augusta. Os fios (in) visíveis da produção capitalista: informalidade e precarização do trabalho. São Paulo: Cortez, 2004.

Recebido em: 17/11/2010

Aprovado em: 21/12/2010 